\title{
Hydrogenation reactions in interstellar $\mathrm{CO}$ ice analogues
}

\section{A combined experimental/theoretical approach}

\author{
G. W. Fuchs, H. M. Cuppen, S. Ioppolo, C. Romanzin, S. E. Bisschop, S. Andersson, \\ E. F. van Dishoeck, and H. Linnartz
}

\begin{abstract}
Raymond \& Beverly Sackler Laboratory for Astrophysics, Leiden Observatory, Leiden University, PO Box 9513, 2300 RA Leiden, The Netherlands

e-mail: linnartz@strw.leidenuniv.nl
\end{abstract}

Received 11 August 2008 / Accepted 11 June 2009

\begin{abstract}
Context. Hydrogenation reactions of $\mathrm{CO}$ in inter- and circumstellar ices are regarded as an important starting point in the formation of more complex species. Previous laboratory measurements by two groups of the hydrogenation of CO ices provided controversial results about the formation rate of methanol.

Aims. Our aim is to resolve this controversy by an independent investigation of the reaction scheme for a range of $\mathrm{H}$-atom fluxes and different ice temperatures and thicknesses. To fully understand the laboratory data, the results are interpreted theoretically by means of continuous-time, random-walk Monte Carlo simulations.

Methods. Reaction rates are determined by using a state-of-the-art ultra high vacuum experimental setup to bombard an interstellar $\mathrm{CO}$ ice analog with $\mathrm{H}$ atoms at room temperature. The reaction of $\mathrm{CO}+\mathrm{H}$ into $\mathrm{H}_{2} \mathrm{CO}$ and subsequently $\mathrm{CH}_{3} \mathrm{OH}$ is monitored by a Fourier transform infrared spectrometer in a reflection absorption mode. In addition, after each completed measurement, a temperature programmed desorption experiment is performed to identify the produced species according to their mass spectra and to determine their abundance. Different $\mathrm{H}$-atom fluxes, morphologies, and ice thicknesses are tested. The experimental results are interpreted using Monte Carlo simulations. This technique takes into account the layered structure of $\mathrm{CO}$ ice.

Results. The formation of both formaldehyde and methanol via CO hydrogenation is confirmed at low temperature $(T=12-20 \mathrm{~K})$. We confirm that the discrepancy between the two Japanese studies is caused mainly by a difference in the applied hydrogen atom flux, as proposed by Hidaka and coworkers. The production rate of formaldehyde is found to decrease and the penetration column to increase with temperature. Temperature-dependent reaction barriers and diffusion rates are inferred using a Monte Carlo physical chemical model. The model is extended to interstellar conditions to compare with observational $\mathrm{H}_{2} \mathrm{CO} / \mathrm{CH}_{3} \mathrm{OH}$ data.
\end{abstract}

Key words. astrochemistry - infrared: ISM - ISM: atoms - ISM: molecules - methods: laboratory

\section{Introduction}

An increasing number of experimental and theoretical studies have focused on the characterisation of solid state astrochemical processes. These studies were triggered by the recognition that many simple and more complex molecules in the interstellar medium are most likely to have formed on the surfaces of dust grains. Astronomical observations, detailed laboratory studies, and progress in UHV surface techniques allow experimental verification of the initial surface reaction schemes, as introduced by Tielens, Hagen, and Charnley (Tielens \& Hagen 1982; Tielens \& Charnley 1997). Recently the formation of water was demonstrated in hydrogenation schemes starting from solid molecular oxygen (Miyauchi et al. 2008; Ioppolo et al. 2008) and the formation of ethanol from acetaldehyde (Bisschop et al. 2007a). The first solid-state astrochemical laboratory studies focused on the formation of formaldehyde and methanol by $\mathrm{H}$-atom bombardment of CO ice. Methanol is observed abundantly in interstellar ices and is considered to be a resource for the formation of more complex molecules through surface reactions and after evaporation in the gas phase (Charnley et al. 1992). The hydrogenation scheme for the solid state formation of methanol was proposed to be

$\mathrm{CO} \stackrel{\mathrm{H}}{\rightarrow} \mathrm{HCO} \stackrel{\mathrm{H}}{\rightarrow} \mathrm{H}_{2} \mathrm{CO} \stackrel{\mathrm{H}}{\rightarrow} \mathrm{H}_{3} \mathrm{CO} \stackrel{\mathrm{H}}{\rightarrow} \mathrm{CH}_{3} \mathrm{OH}$.
Laboratory studies of $\mathrm{H}$-atom bombardment of $\mathrm{CO}$ ice were performed independently by two groups (Hiraoka et al. 2002; Watanabe \& Kouchi 2002). Hiraoka et al. (2002) observed only formaldehyde formation, whereas Watanabe \& Kouchi (2002) also found efficient methanol production. In a series of papers, these conflicting results were discussed (Hiraoka et al. 2002; Watanabe et al. 2003, 2004) and the prevailing discrepancy between results was proposed to be a consequence of different experimental conditions, most noticeable the adopted $\mathrm{H}$-atom flux (Hidaka et al. 2004). Understanding the solid-state formation route to methanol became even more important following an experimental finding that the gas-phase formation route via ionneutral reactions is less efficient than previously estimated and cannot explain the observed interstellar abundances (Geppert et al. 2005; Garrod et al. 2006).

Deuteration experiments were also performed on $\mathrm{CO}$ ice, which confirmed the formation of both fully deuterated formaldehyde and methanol, but with substantially lower reaction rates (Nagaoka et al. 2005; Watanabe et al. 2006). In the presence of both hydrogen and deuterium it was suggested that first normal methanol forms and is then gradually converted in the deuterated species by exchange reactions.

The present paper strongly supports the flux argument given by Hidaka et al. (2004). Furthermore, we present a systematic 


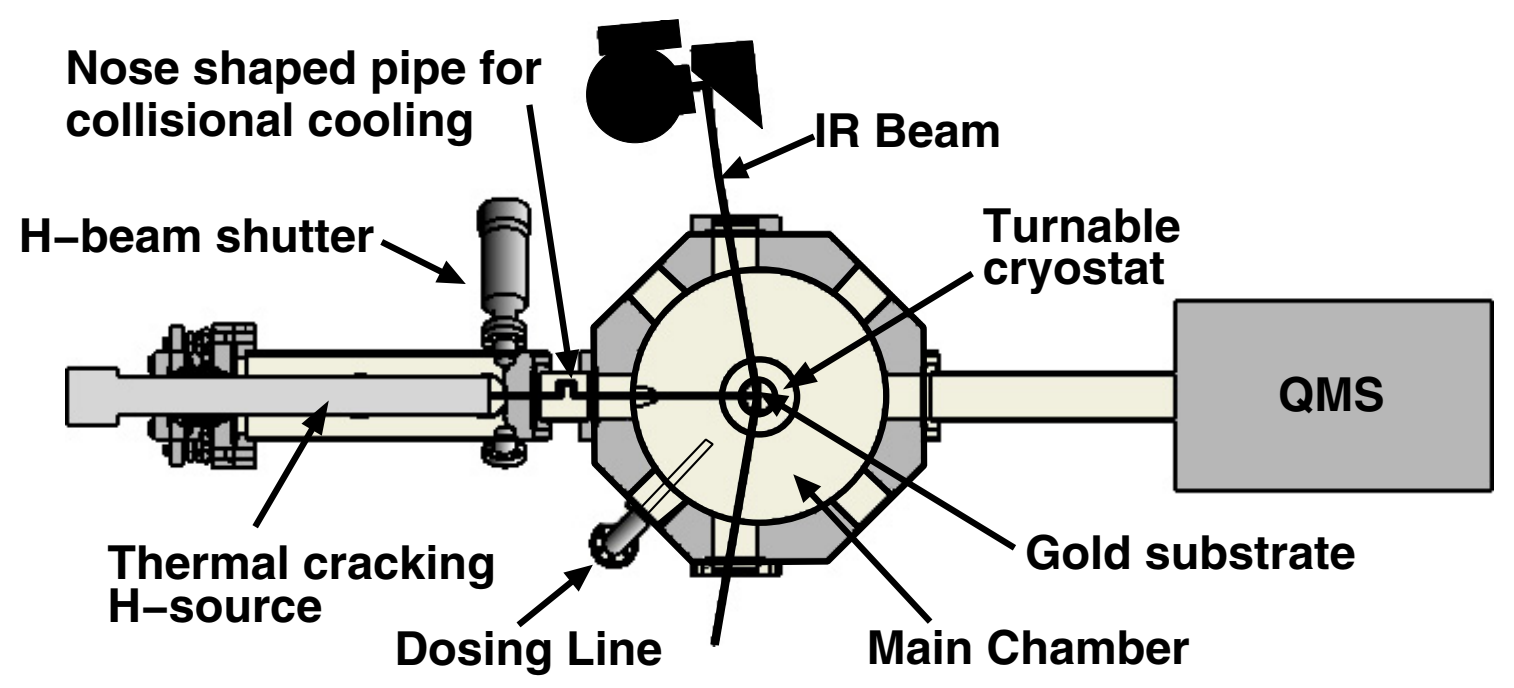

Fig. 1. Schematic representation of the experimental setup. CO ice is deposited through the dosing line and the products are monitored by means of infrared spectroscopy and quadrupole mass spectroscopy (QMS).

study of the physical dependencies involved in the CO-ice hydrogenation to place previous work in a context that allows an extension of solid state astrochemical processes to more complex species. Special emphasis is placed on the flux and temperature dependence of the formation rate. An analysis of the spectral changes of $\mathrm{CO}$ ice during hydrogenation is included to provide insight into the structure of the reactive layer. Furthermore, Monte Carlo simulations are presented that allow us to interpret the experimental results in greater detail and to vary parameters that are difficult to study independently by experiment. We conclude with a simulation of $\mathrm{H}_{2} \mathrm{CO} / \mathrm{CH}_{3} \mathrm{OH}$ formation under interstellar conditions, in particular for low $\mathrm{H}$-atom fluxes. The outcome is compared with astronomical observations.

\section{Experimental procedure}

The experiments are performed under UHV conditions. The room temperature base pressure of the vacuum system is better than $3 \times 10^{-10}$ mbar. Figure 1 shows a schematic representation of the setup (see Ioppolo et al. (2008) for additional information). Amorphous CO ices ranging from a few to several monolayers are grown on a gold coated copper substrate that is located at the centre of the main vacuum chamber and mounted on the tip of a cold finger of a $10 \mathrm{~K} \mathrm{He}$-cryostat. The temperature of the ice can be controlled between $12.0 \mathrm{~K}$ and $300 \mathrm{~K}$ with $0.5 \mathrm{~K}$ relative precision between experiments. The absolute accuracy is better than $2 \mathrm{~K}$. During deposition, the layer thickness is monitored by simultaneous recording of reflection absorption infrared (RAIR) spectra. To exclude the effects of potential pollution, ices are grown using $\mathrm{CO},{ }^{13} \mathrm{CO}$, or $\mathrm{C}^{18} \mathrm{O}$ isotopologues.

During the experiment the ice layers are exposed to a hydrogen atom beam. The atoms are produced by a well characterised commercial thermal-cracking source (Tschersich \& von Bonin 1998; Tschersich 2000) that provides H-atom fluxes on the sample surface of between $10^{12}$ and $10^{14}$ atoms $\mathrm{cm}^{-2} \mathrm{~s}^{-1}$. By comparison, the Hiraoka group used fluxes below $10^{13}$ atoms cm $\mathrm{cm}^{-2} \mathrm{~s}^{-1}$ and the Watanabe group worked in the $10^{14}-10^{15}$ atoms $\mathrm{cm}^{-2} \mathrm{~s}^{-1}$ regime. The hot $(\sim 2000 \mathrm{~K})$ hydrogen atoms are cooled to room temperature by surface collisions in a nose-like shaped quartz pipe between the atomic source and the ice sample. In this way, hot hydrogen atoms cannot affect the ice directly. $\mathrm{H}$-atom recombination in this connecting pipe results in a lower final flux. Details about the flux determination are given in Appendix A. The absolute fluxes are estimated to be within a factor of two and the relative fluxes to within $50 \%$.

The relatively high temperature of the incident atoms of $300 \mathrm{~K}$ does not affect the process; previous experiments with colder $\mathrm{H}$ atoms did not show any substantial temperature dependence because the atoms are immediately thermalized on the surface (Watanabe \& Kouchi 2002). It is argued that the surface is covered with a thin layer of hydrogen molecules under these conditions. These molecules are either formed on the surface or originate from the partially dissociated beam. Since the incoming atoms have to penetrate this cold $\mathrm{H}_{2}$ layer, they are thermally adjusted to the surface temperature once they come in contact with the $\mathrm{CO}$ molecules.

Information about the reaction products is obtained using two complementary techniques. During the H-atom bombardment, reactants and products are monitored by recording RAIR spectra. The RAIR spectra are recorded using a Fourier transform infrared spectrometer with 1 and $4 \mathrm{~cm}^{-1}$ resolution and covering the spectral region in which $\mathrm{CO}\left(2143(\mathrm{~s}) \mathrm{cm}^{-1}\right)$, formaldehyde (1732 (s), 1479, and $2812(\mathrm{~m})$, and 1246, 1175, 2991, 2880, and $2812(\mathrm{mw}) \mathrm{cm}^{-1}$ ) and methanol (1035 (s) and $1125(\mathrm{w}) \mathrm{cm}^{-1}$ ) exhibit strong (s), medium (m), or weak (w) absorption bands. The intensity of spectral features is directly related to the density in the ice. The products are monitored by mass spectrometry using temperature programmed desorption (TPD) once a hydrogenation experiment is completed.

\section{Experimental results}

\subsection{A sample experiment}

To illustrate the experimental method, we start by discussing a sample experiment in which a CO ice of $8 \times 10^{15}$ molecules $\mathrm{cm}^{-2}$ is bombarded with $\mathrm{H}$ atoms with a flux of $5 \times 10^{13} \mathrm{~cm}^{-2} \mathrm{~s}^{-1}$ for three hours at a surface temperature of $12.0 \mathrm{~K}$. This corresponds to a fluence of $5.4 \times 10^{17} \mathrm{~cm}^{-2}$. Figure 2 shows the RAIR difference spectrum $(\triangle A b s)$ after these three hours of exposure (after - before). The $\mathrm{CO}$, the $\mathrm{H}_{2} \mathrm{CO}$ and the $\mathrm{CH}_{3} \mathrm{OH}$ spectral signatures are indicated with respect to the spectrum recorded before the $\mathrm{H}$-atom bombardment started. The $\mathrm{CO}$ appears as a negative band, indicating its use-up, and the other bands are positive, 


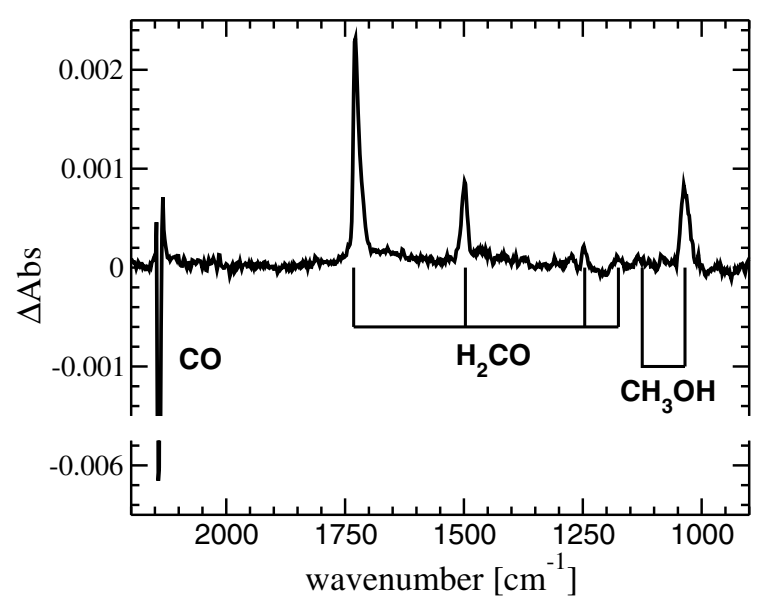

Fig. 2. RAIR difference spectrum of a $\mathrm{CO}$ ice at $12.0 \mathrm{~K}$ exposed to $5.4 \times$ $10^{17} \mathrm{~cm}^{-2} \mathrm{H}$ atoms at a flux of $5 \times 10^{13} \mathrm{~cm}^{-2} \mathrm{~s}^{-1}$. The spectrum after $\mathrm{CO}$ deposition is used as the reference spectrum. Note that the $\mathrm{CO}$ peak reaches an absorbance difference of -0.006 .

indicating the formation of $\mathrm{H}_{2} \mathrm{CO}$ and $\mathrm{CH}_{3} \mathrm{OH}$. Neither the intermediate species, $\mathrm{HCO}$ and $\mathrm{H}_{3} \mathrm{CO}$, nor more complex species are observed.

The column density $N_{X}$ (molecules $\mathrm{cm}^{-2}$ ) of species $X$ in the ice is calculated using

$N_{X}=\frac{\int A(v) \mathrm{d} v}{S_{X}}$,

where $A(v)$ is the wavelength dependent absorbance. Since literature values of transmission band strengths cannot be used in reflection measurements, an apparent absorption band strength, $S_{X}$ of species $X$ is calculated from a calibration experiment in which an ice layer of species $X$ desorbs at constant temperature until the sub-monolayer regime. This is illustrated in Fig. 3, which shows the decrease in integrated absorbance of $\mathrm{CO}$ and $\mathrm{CH}_{3} \mathrm{OH}$ during such an experiment. The arrows in the graph indicate the deviation onset from constant desorption, which marks the transition point from the multi- to sub-monolayer regime. The apparent absorption band strengths of $\mathrm{CO}$ and $\mathrm{CH}_{3} \mathrm{OH}$ $\left(1035 \mathrm{~cm}^{-1}\right)$ thus obtained are setup specific. The corresponding uncertainty in the band strengths remains within $50 \%$. The ratio of $S_{\mathrm{CO}}$ to $S_{\mathrm{CH}_{3} \mathrm{OH}}$ in our reflection experiment is similar to the transmittance ratio, 0.85 . The value for $S_{\mathrm{H}_{2} \mathrm{CO}}$ is obtained by assuming mass balance

$N_{\mathrm{CO}}(t)+N_{\mathrm{CH}_{3} \mathrm{OH}}(t)=-\frac{\int A(v) \mathrm{d} v}{S_{\mathrm{H}_{2} \mathrm{CO}}}$

for a set of different experiments. In addition, the results discussed in the present paper are all in a regime where the proportionality relation (Teolis et al. 2007) still holds $(<3 \times$ $10^{16}$ molecules $\mathrm{cm}^{-2}$ ).

The CO band shape can change when molecules other than $\mathrm{CO}$ are formed. Figure 4 shows the $2143 \mathrm{~cm}^{-1}$ IR peak before and after the $\mathrm{H}$-atom exposure. A clear decrease in the peak height can be observed caused by the use-up of $\mathrm{CO}$ during the experiment, as expected. However, an additional peak appears at $2135 \mathrm{~cm}^{-1}$ (see inset Fig. 4), which is due to a $\mathrm{CH}_{3} \mathrm{OH}-\mathrm{CO}$ ice interaction. Transmission IR spectra of a $\mathrm{CH}_{3} \mathrm{OH}: \mathrm{CO}$ mixture show a band at $2136 \mathrm{~cm}^{-1}$ (Bisschop 2007; Palumbo \& Strazzulla 1993). When the methanol bands grow, the band at $2135 \mathrm{~cm}^{-1}$ also increases. Figure 5 shows how the peak position of $\mathrm{CO}$ shifts with the methanol content in the reflection

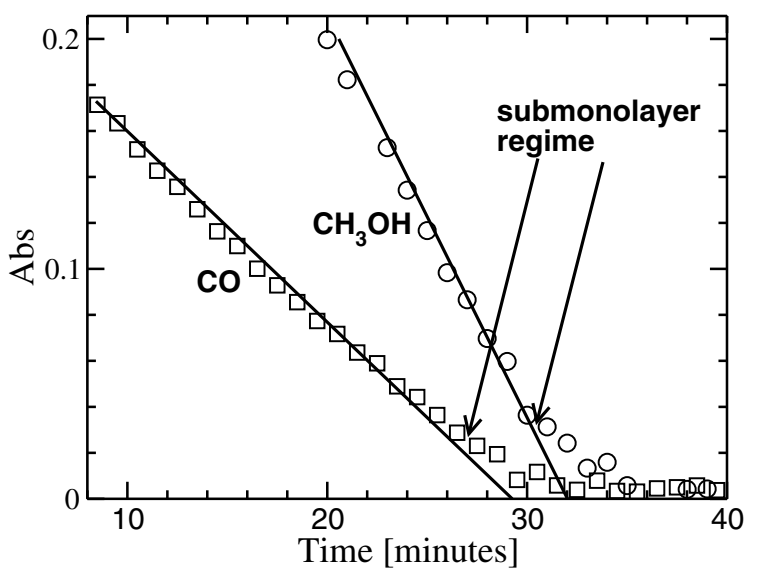

Fig. 3. The decrease in integrated absorbance of $\mathrm{CO}$ and $\mathrm{CH}_{3} \mathrm{OH}$ $\left(1035 \mathrm{~cm}^{-1}\right)$ following desorption at a constant temperature of 29 and $135 \mathrm{~K}$, respectively. The arrows indicate the transition points from the multi- to sub-monolayer regime.

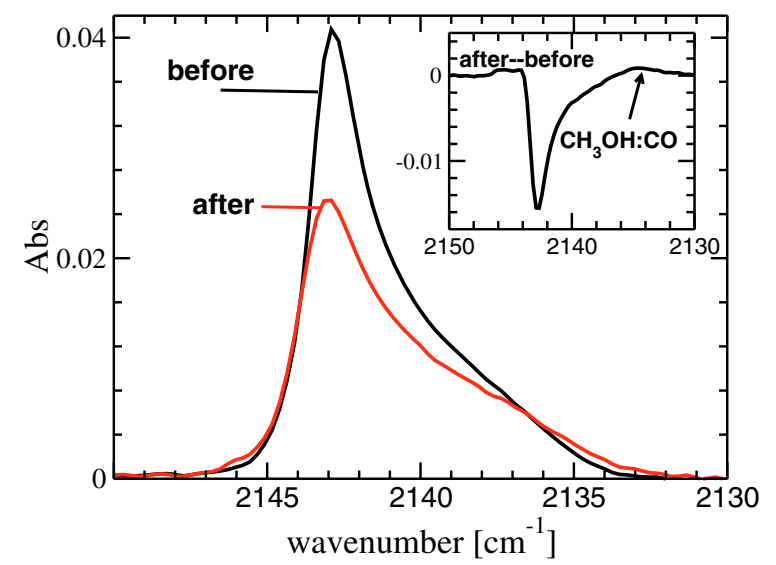

Fig. 4. Spectral change of the CO $2143 \mathrm{~cm}^{-1}$ RAIR band before and after $\mathrm{H}$-atom bombardment. The inset shows the corresponding difference spectrum.

spectra. The RAIR spectra on which this graph is based, are taken for ice layers that are formed by co-deposition of $\mathrm{CO}$ and $\mathrm{CH}_{3} \mathrm{OH}$ of known ratio. The $\mathrm{CO}$ stretching mode in $\mathrm{H}_{2} \mathrm{O}: \mathrm{CO}$ and $\mathrm{NH}_{3}: \mathrm{CO}$ mixtures shows a similar behaviour (Sandford et al. 1988; Bouwman et al. 2007). As for both $\mathrm{H}_{2} \mathrm{O}$ and $\mathrm{NH}_{3}, \mathrm{CH}_{3} \mathrm{OH}$ is able to form hydrogen bonds and these hydrogen bonds most likely cause the redshift of the $\mathrm{CO}$ band. By comparing the position of the peak in Fig. 4 at $2135 \mathrm{~cm}^{-1}$ to the data in Fig. 5, we can constrain the methanol fraction in the top layers, assuming that the formed $\mathrm{CH}_{3} \mathrm{OH}: \mathrm{CO}$ mixture has the same spectral behaviour as the deposited mixtures. The observed data after three hours correspond to a $\mathrm{CH}_{3} \mathrm{OH}: \mathrm{CO}$ mixture of at least $90 \%$. This means that the top layer of the ice is completely converted into $\mathrm{H}_{2} \mathrm{CO}$ and $\mathrm{CH}_{3} \mathrm{OH}$ and that no or very little additional mixing with $\mathrm{CO}$ occurs. For the $\mathrm{H}_{2} \mathrm{CO}$ and $\mathrm{CH}_{3} \mathrm{OH}$ band, no spectral changes are observed during the experiments.

To quantify the use-up of $\mathrm{CO}$ and the formation of new products, we have to assume that the apparent absorption band strength is constant during an experiment, i.e., independent of the ice composition. Bouwman et al. (2007) found that the band strength of the $2143 \mathrm{~cm}^{-1} \mathrm{CO}$ feature is indeed unaffected within the experimental error by the water content in $\mathrm{H}_{2} \mathrm{O}$ :CO-ice mixtures up to $4: 1$. The band strength is expected to behave similarly for a $\mathrm{CO}: \mathrm{CH}_{3} \mathrm{OH}$-mixture. Furthermore, if the band strength is 


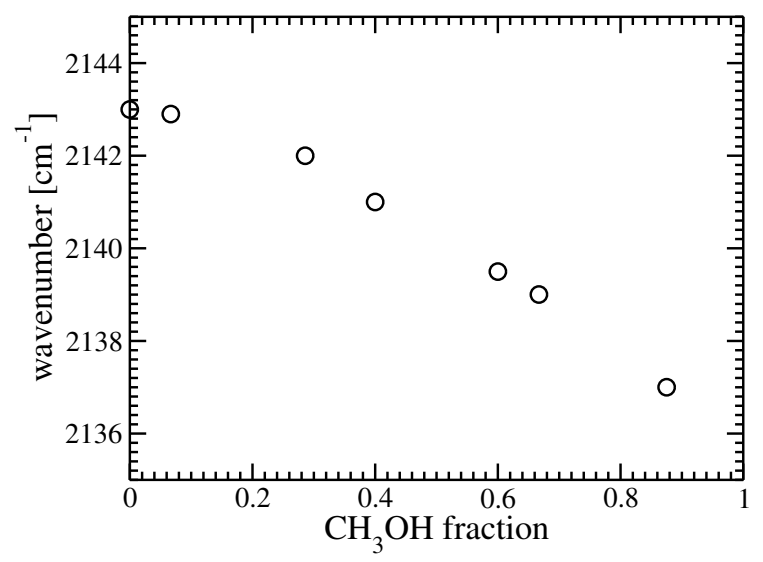

Fig. 5. CO RAIR band position as a function of $\mathrm{CH}_{3} \mathrm{OH}$ content in a $\mathrm{CO}: \mathrm{CH}_{3} \mathrm{OH}$ mixed ice obtained by codeposition experiments.

strongly affected by the ice composition, the total ice thickness determined using a constant band strength should vary in time, whereas the real thickness is constant. Since this does not occur, we estimate that the change in band strength caused by the change in ice composition is negligible and well within our margins of error.

Figure $6 \mathrm{a}$ shows the time evolution of the integrated $\mathrm{CO}$, $\mathrm{H}_{2} \mathrm{CO}$, and $\mathrm{CH}_{3} \mathrm{OH}$ signals in symbols. It shows how the amount of $\mathrm{CO}$ decreases as the abundance of $\mathrm{H}_{2} \mathrm{CO}$ increases for four different temperatures. After bombardment with $1 \times$ $10^{17} \mathrm{H}$ atoms $\mathrm{cm}^{-2}$, the formation of methanol kicks off at the expense of the growth of the $\mathrm{H}_{2} \mathrm{CO}$ abundance. Similar trends of abundance evolution as a function of fluence are reported by Watanabe et al. (2006). This indicates that the fluence is determined with relatively high accuracy since in both experiments different atomic sources (Tschersich vs. microwave induced plasma) and different calibration methods are used.

\subsection{Flux dependence}

As mentioned in the introduction, the apparent discrepancy between the results by Hiraoka et al. (2002) and Watanabe \& Kouchi (2002) has been attributed to a difference in the $\mathrm{H}$-atom flux used in the respective experiments. The setup in our laboratory is able to cover the entire flux range from $10^{12}$ to $10^{14} \mathrm{~cm}^{-2} \mathrm{~s}^{-1}$. For high flux, both formaldehyde and methanol are formed as can be seen in Figs. 2 and 6 and in the corresponding work of Watanabe \& Kouchi (2002).

A difference spectrum of a similar experiment but with a much lower flux of $10^{12} \mathrm{~cm}^{-2} \mathrm{~s}^{-1}$ is plotted in Fig. 7. The exposure time here is four hours to reach a higher total fluence of $1 \times 10^{16} \mathrm{~cm}^{-2}$, which is still significantly less than the sample experiment shown in Fig. 2. Note that the vertical scales in Figs. 2 and 7 cover the same range. For longer exposures, surface contamination would become a problem, but methanol features would eventually become detectable. As Fig. 7 clearly shows, a smaller fraction of $\mathrm{CO}$ is transformed into $\mathrm{H}_{2} \mathrm{CO}$ and the sensitivity of the RAIR spectrometer is not sufficiently high to confirm the formation of $\mathrm{CH}_{3} \mathrm{OH}$ in these circumstances. TPD, however, is more sensitive as a diagnostic tool, although harder to use for a quantitative or time resolved analysis. Figure 8 plots several TPD spectra. It shows a small methanol desorption peak around $150 \mathrm{~K}$. We checked experimentally that the carrier of this peak is indeed formed in the ice during the hydrogen exposure and that the observed $\mathrm{CH}_{3} \mathrm{OH}$ is not a contaminant in the UHV

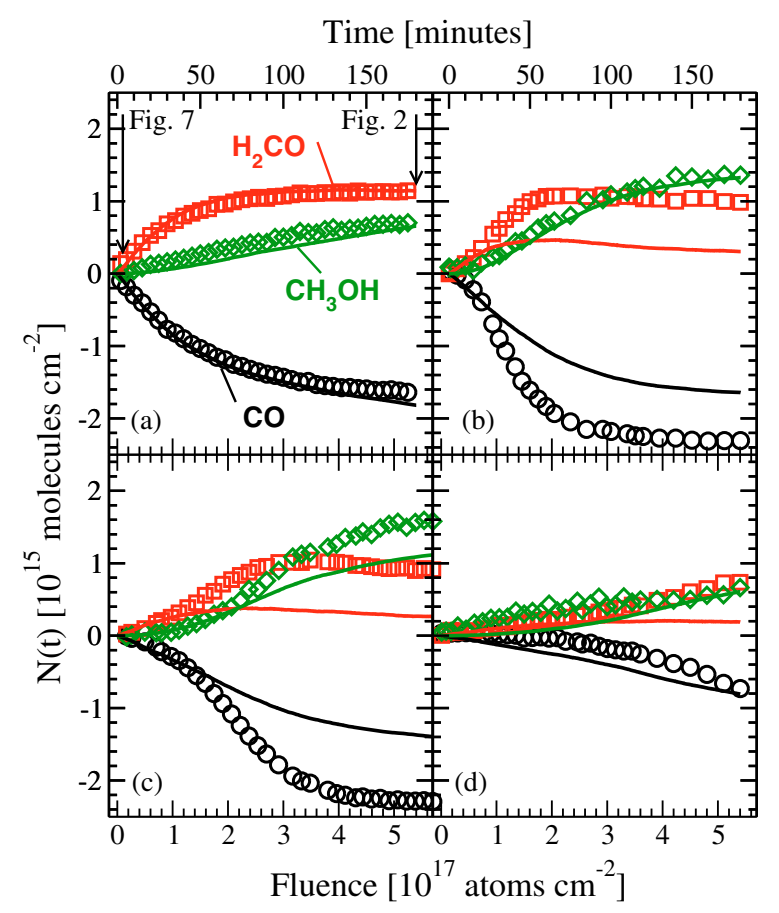

Fig. 6. Time evolution of the surface abundance (in molecules $\mathrm{cm}^{-2}$ ) of $\mathrm{CO}, \mathrm{H}_{2} \mathrm{CO}$ and $\mathrm{CH}_{3} \mathrm{OH}$ during $\mathrm{H}$-atom bombardment of $\mathrm{CO}$ ice with a $\mathrm{H}$-atom flux of $5 \times 10^{13} \mathrm{~cm}^{-2} \mathrm{~s}^{-1}$ at surface temperatures of $12.0 \mathrm{~K} \mathrm{a}$ ), $13.5 \mathrm{~K} \mathrm{~b}), 15.0 \mathrm{~K} \mathrm{c}$ ), and $16.5 \mathrm{~K} \mathrm{~d}$ ). Experimental data (symbols) and Monte Carlo simulation results (solid lines) are shown as well.

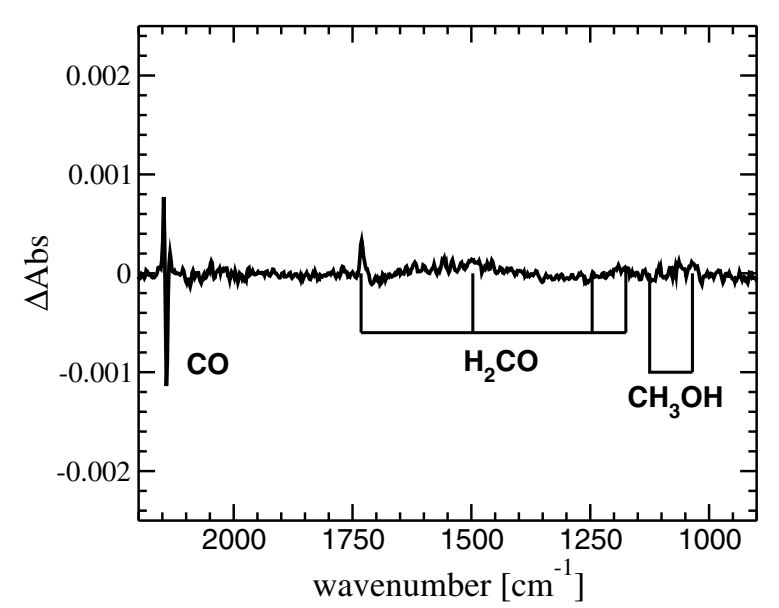

Fig. 7. RAIR spectrum of a $\mathrm{CO}$ ice at $12.0 \mathrm{~K}$ exposed to a fluence of $1 \times$ $10^{16} \mathrm{H}$ atoms $\mathrm{cm}^{-2}$.

chamber. This is a strong indication that the formation mechanism of formaldehyde and methanol does not fundamentally change with varying flux. The $\mathrm{H}_{2} \mathrm{O}$ desorption at $20-30 \mathrm{~K}$ originates in frozen background water on the surrounding parts of the cryohead.

The arrows in Fig. 6a indicate the corresponding fluences for the low and high flux experiments shown in Figs. 7 and 2, respectively. From this, it is immediately apparent that only a limited amount of methanol can be formed under low flux circumstances. Note that Hiraoka et al. (2002) probably used an even lower fluence since their exposure time was four times shorter than in our experiment. In addition, they used a slightly lower temperature of $10 \mathrm{~K}$. 


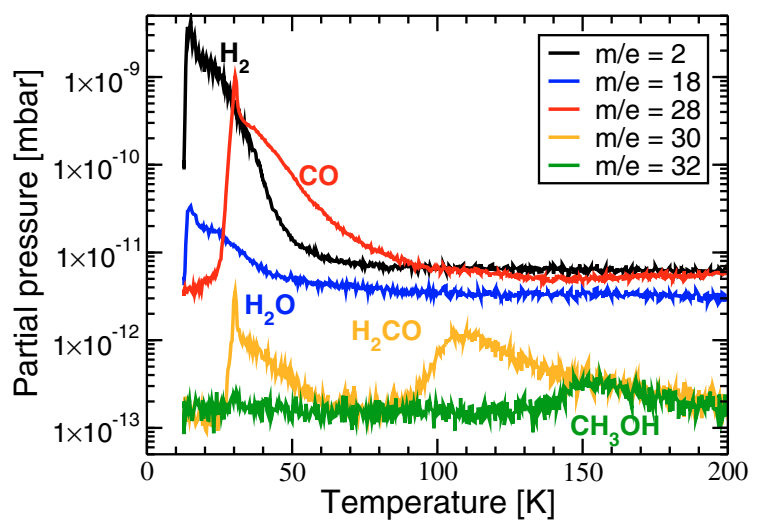

Fig. 8. The TPD spectra corresponding to Fig. 7.

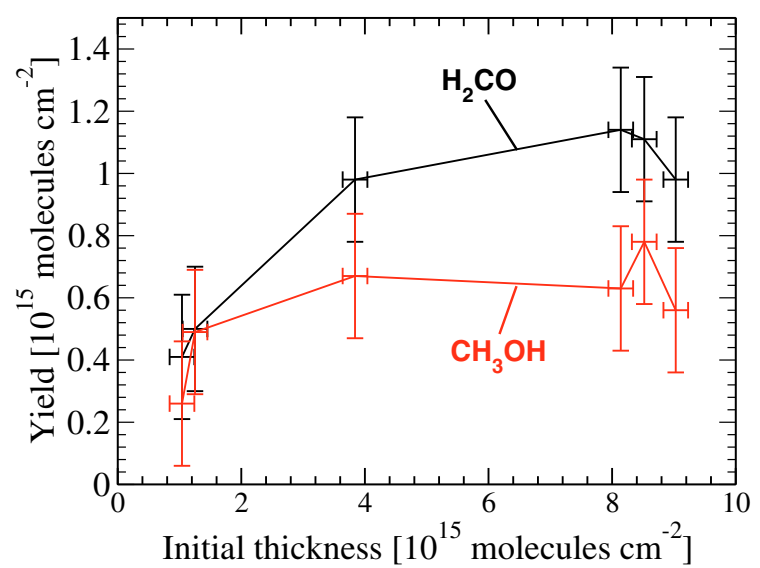

Fig. 9. The absolute reaction yield of $\mathrm{H}_{2} \mathrm{CO}$ and $\mathrm{CH}_{3} \mathrm{OH}$ after a fluence of $5.4 \times 10^{17} \mathrm{H}$ atoms $\mathrm{cm}^{-2}$ as a function of the layer thickness for experiments at $12.0 \mathrm{~K}$.

\subsection{Thickness dependence}

The effect of the initial layer thickness on the formation yield of $\mathrm{H}_{2} \mathrm{CO}$ and $\mathrm{CH}_{3} \mathrm{OH}$ is investigated by repeating the sample experiment for different $\mathrm{CO}$ layer thicknesses. Figure 9 shows the absolute reaction yield after a fluence of $5.4 \times 10^{17} \mathrm{H}_{\text {atoms cm}}{ }^{-2}$ as a function of the layer thickness. In all cases, a steady state value for $\mathrm{H}_{2} \mathrm{CO}$ is reached for this fluence. The figure clearly shows that for CO layers thicker than $4 \times 10^{15}$ molecules $\mathrm{cm}^{-2}$, the absolute yield is layer thickness independent and the results are reproducible within the measurement error. The combined $\mathrm{H}_{2} \mathrm{CO}$ and $\mathrm{CH}_{3} \mathrm{OH}$ yield of $2 \times 10^{15}$ molecules $\mathrm{cm}^{-2}$ is lower than the $4 \times 10^{15}$ molecules $\mathrm{cm}^{-2}$ penetration column. From these experiments, we conclude that the penetration column of the $\mathrm{H}$ atoms into the $\mathrm{CO}$ ice is at most $4 \times 10^{15}$ molecules $\mathrm{cm}^{-2}$ at $12.0 \mathrm{~K}$. This corresponds to 4 monolayers (ML) of solid (bulk) $\mathrm{CO}$ molecules. At least half of the $\mathrm{CO}$ molecules in the active layer is converted into $\mathrm{H}_{2} \mathrm{CO}$ and $\mathrm{CH}_{3} \mathrm{OH}$. The determination of the penetration column by this experiment is only an upper limit because of the low thickness resolution in Fig. 9. It however agrees with the previous estimate of nearly $100 \%$ conversion.

\subsection{Temperature dependence}

Several experiments for different surface temperatures have been performed. The initial layer thickness and flux values are comparable to the values used in the sample experiment. Figures $6 \mathrm{~b}-\mathrm{d}$ show the results for hydrogenation experiments at 13.5, 15.0, and $16.5 \mathrm{~K}$, respectively. These clearly indicate the very different evolution of $\mathrm{CO}, \mathrm{H}_{2} \mathrm{CO}$, and $\mathrm{CH}_{3} \mathrm{OH}$ abundance with temperature. Table 1 gives the initial formation rate of formaldehyde (slope at $t=0$ ) and the final $\mathrm{H}_{2} \mathrm{CO}$ and $\mathrm{CH}_{3} \mathrm{OH}$ yields, and also indicates whether or not a steady state is reached. The table shows that at early times, the formation rate of $\mathrm{H}_{2} \mathrm{CO}$ is much lower for higher temperatures than for $12.0 \mathrm{~K}$. We will return to this point later. The final yield of $\mathrm{CH}_{3} \mathrm{OH}$ is however larger at 13.5 and $15.0 \mathrm{~K}$. For $T>15 \mathrm{~K}$, the production rate of $\mathrm{H}_{2} \mathrm{CO}$ is simply so low that a steady state is not reached. Minimal amounts of formed methanol were also detected in experiments at 18.0 and $20.0 \mathrm{~K}$, but since some $\mathrm{CO}$ desorption and redeposition occurs at these temperatures, they are not presented here for a quantitative discussion.

The appearance of the extra CO band at $2135 \mathrm{~cm}^{-1}$ indicates that for temperatures between 12.0 and $15.0 \mathrm{~K}$ a nearly pure methanol layer is formed. We expect a similar behaviour for formaldehyde. This means that the active CO layer involved in the reactions can be determined directly from the steady state yield of $\mathrm{H}_{2} \mathrm{CO}$ and $\mathrm{CH}_{3} \mathrm{OH}$. This active layer increases with temperature indicating that the penetration column of $\mathrm{H}$ atoms into $\mathrm{CO}$ ice increases with temperature as one would expect. The CO molecules in the ice are more mobile at higher temperatures making it easier for $\mathrm{H}$ atoms to penetrate the $\mathrm{CO}$ ice, since the ice becomes less rigid. Note that the absolute temperature calibration in the set-up of Watanabe and ours appears to differ by $1-2 \mathrm{~K}$ (comparing Fig. 3 in Watanabe et al. 2006 and Fig. 6 here), but the observed trends are identical.

\section{Monte Carlo simulations}

\subsection{The method}

To infer the underlying mechanisms leading to the formation of methanol, a detailed physical-chemical model is required. The present section discusses an approach based on the continuous time, random-walk Monte Carlo simulation technique. This method differs from previous studies based on rate equations and enables the study of surface processes to be performed in more detail. In addition, it provides a clearer understanding about what occurs physically on the surface. In contrast to an analysis using rate laws, the Monte Carlo method determines the $\mathrm{H}$ surface abundance by taking into account the layered structure of the ice, the H-atom flux, diffusion, reaction and desorption. This allows an extension of the results to conditions with much lower fluxes such as in the interstellar medium (ISM). For a detailed description of the method and program, we refer to Cuppen \& Herbst (2007).

During a simulation, a sequence of processes - hopping, desorption, deposition, and reaction - is performed, where this sequence is chosen by means of a random number generator in combination with the rates for the different processes. First, an initial ice layer is created by deposition of $\mathrm{CO}$ on a surface. The resulting surface roughness of this layer depends on temperature and flux. For the experimental conditions simulated here, the $\mathrm{CO}$ ice is compact with a maximum height difference across the surface of only 2-3 monolayers. Hydrogen atoms and hydrogen molecules are subsequently deposited, following their relative abundance in the $\mathrm{H}$-atom flux, at an angle perpendicular to the surface to mimic the experimental conditions. They move, react, and desorb according to rates of a form similar to that used in gas-grain models

$R_{x}=A \exp \left(-\frac{E_{x}}{T}\right)$ 
Table 1. The production rate and yield of $\mathrm{H}_{2} \mathrm{CO}$ and the yield of $\mathrm{CH}_{3} \mathrm{OH}$.

\begin{tabular}{cccccc}
\hline \hline $\begin{array}{c}T \\
(\mathrm{~K})\end{array}$ & $\begin{array}{c}\text { Rate }\left(\mathrm{H}_{2} \mathrm{CO}\right)_{t=0}{ }^{a} \\
\left(10^{-3} \text { molec./H atom }\right)\end{array}$ & $\begin{array}{c}\text { Yield }\left(\mathrm{H}_{2} \mathrm{CO}\right)^{b} \\
\left(10^{15} \text { molec. } \mathrm{cm}^{-2}\right)\end{array}$ & $\begin{array}{c}\text { Yield }\left(\mathrm{CH}_{3} \mathrm{OH}\right)^{b} \\
\left(10^{15} \text { molec. } \mathrm{cm}^{-2}\right)\end{array}$ & Steady state & $\begin{array}{c}\text { Calc. pen. column } \\
\left(10^{15} \mathrm{molec}^{c} \mathrm{~cm}^{-2}\right)\end{array}$ \\
\hline 12.0 & 9.0 & 1.2 & 0.8 & yes & 2.0 \\
13.5 & 7.3 & 1.0 & 1.4 & yes & 2.4 \\
15.0 & 3.2 & 0.9 & 1.6 & yes & 2.5 \\
16.5 & 1.1 & 0.8 & 0.6 & no & \\
18.0 & 1.0 & 0.5 & 0.2 & no & \\
20.0 & 0.9 & 0.4 & 0.1 & no & \\
\hline
\end{tabular}

${ }^{a}$ Rate at $t=0$ determined from slope.

${ }^{b}$ Yield after three hours of $\mathrm{H}$-atom exposure which corresponds to a fluence of $5.4 \times 10^{17} \mathrm{H}$ atoms cm${ }^{-2}$. The steady state yield is not reached for all temperatures (fifth column).

${ }^{c}$ Penetration column obtained from Cols. 3, 4, and 6.

where $E_{x}$ is the activation energy for process $X$, and $A$ is the preexponential factor for which a constant number of $v \sim k T / h=$ $2 \times 10^{11} \mathrm{~s}^{-1}$ is used. The activation energies are not well determined ab initio or by experiment. The desorption energies are determined from the binding energy, as explained below, and depend on an energy parameter $E$. The barriers for reaction are used as a parameter to fit the data. The barrier for hopping (diffusion) from site $i$ to $j$ is assumed to be

$E_{\mathrm{hop}}(i, j)=\xi E+\frac{\Delta E_{\mathrm{bind}}(i, j)}{2}$.

This expression ensures microscopic reversibility between the different types of sites. The parameter $\xi$ is another input parameter, which is varied between simulations. Little quantitative information is available about diffusion rates on these kind of surfaces, which makes the value of $\xi$ uncertain.

Diffusion into the ice is also considered. Minimum energy path calculations suggest that $\mathrm{CO}$ and $\mathrm{H}$ can swap position enabling an $\mathrm{H}$ atom to penetrate into the $\mathrm{CO}$ ice (see Appendix B). The barrier for this process strongly depends on the layer in which the $\mathrm{H}$ atom is situated. In the simulations, the barrier for this event is $\left(350+2\left(z_{1}+z_{2}\right)\right) \mathrm{K}$ for an $\mathrm{H}$ atom to swap between layer $z_{1}$ and $z_{2}$. This compares to a hopping barrier of $E_{\text {hop }}^{\mathrm{H} \text {,flat } \rightarrow \text { flat }}=256 \mathrm{~K}$ and a desorption energy of $E_{\text {bind }}^{\mathrm{H} \text {,flat }}=320 \mathrm{~K}$ (see next section). Hiraoka et al. (1998) found that hydrogen atoms can relatively easily diffuse through the $\mathrm{CO}$ ice. Moreover, the current experiments show that hydrogen atoms can penetrate into a maximum of four monolayers for $12.0 \mathrm{~K}$. Hydrogen atoms are also allowed to swap with formaldehyde and methanol, but here the initial barrier is chosen to be higher ( 450 and $500 \mathrm{~K}$ ) since these species are heavier and are more strongly bound within the ice matrix.

\subsection{The CO ice layer}

Although the experimental CO layers are probably amorphous (Kouchi 1990), crystalline layers are used in the Monte Carlo simulations discussed here. In this way, a lattice-gas Monte Carlo method can be used, which enables far longer simulation times than in off-lattice methods. We expect the crystalline assumption to be reasonable since the local structure of the CO layers is probably close to crystallinity. The energy released during deposition may help the molecules to rearrange slightly, leading to micro-crystalline domains. The $\alpha$-CO structure (Vegard $1930)$ is used with layers in the (110) orientation. The dominant faces of a CO crystal will have this crystallographic orientation. The CO surface consists of alternating carbon and oxygen terminated bi-layers. In the bulk configuration, each $\mathrm{CO}$ molecule has 14 nearest neighbours: five in layers below, five in layers above, and four in the same layer. The additive energy contribution of these neighbours is $2 E$ for the layers below and $E$ for the neighbours in the same layer or of lower $z$, where $z$ is the depth in layers with respect to the top layer. The different treatment for sites below the particle is to add a contribution for longer range interactions from the ice layer. $E$ is chosen to be $32 \mathrm{~K}$ for atomic hydrogen, and $63 \mathrm{~K}$ for $\mathrm{CO}$. This leads to a binding energy of $E_{\text {bind }}^{\mathrm{H} \text { ffat }}=320 \mathrm{~K}$ for $\mathrm{H}$ on top of a flat $\mathrm{CO}$ ice layer, and $E_{\text {bind }}^{\mathrm{H}, \text { layer }}=448 \mathrm{~K}$ and $E_{\text {bind }}^{\mathrm{CO} \text { layer }}=882 \mathrm{~K}$ for $\mathrm{H}$ and $\mathrm{CO}$, respectively, embedded in a CO layer. These values agree very well with binding energies obtained by calculations using accurate $\mathrm{H}-\mathrm{CO}$ and $\mathrm{CO}-\mathrm{CO}$ potentials of 320,440 , and $850 \mathrm{~K}$, respectively (see Appendix B).

\subsection{Comparison to the experiment}

The solid lines in Fig. 6 represent the results from the Monte Carlo calculations. The exact mechanisms included in these simulations are discussed in more detail in the following sections. The resulting time evolution series are in very good agreement for $12.0 \mathrm{~K}$. The agreement for 13.5, 15.0, and $16.5 \mathrm{~K}$ is far less good, probably because of missing mechanisms that promote the penetration into the ice. In the current simulations, only swapping of species is included. Because of the thermal motion of the $\mathrm{CO}$ molecules, "real" penetration in which the $\mathrm{H}$ atoms penetrate in the $\mathrm{CO}$ matrix may also be possible. The shape of the curves is reproduced and only the $\mathrm{H}_{2} \mathrm{CO}$ abundance levels off at too low yields.

The main parameters varied to fit the experimental data are the reaction barriers and the diffusion rates. The best-fit model barriers are summarised in Table 2. Since the intermediate species $\mathrm{HCO}$ and $\mathrm{H}_{3} \mathrm{CO}$ are not experimentally detected, the barriers for hydrogenation of these species are significantly lower than for the other two reactions, presumably even zero. The $\mathrm{HCO}$ and $\mathrm{H}_{3} \mathrm{CO}$ abundances stay below detectable levels in the simulations. The reaction barriers for $\mathrm{H}+\mathrm{CO}$ and $\mathrm{H}+$ $\mathrm{H}_{2} \mathrm{CO}$ are temperature dependent and increase with temperature. Our values are in good absolute agreement with the barriers found by Awad et al. (2005), who also found a similar temperature behaviour. Their values were obtained using a rate equation analysis for $T=10,15$, and $20 \mathrm{~K}$ using the data from Watanabe et al. (2006). The temperature dependence suggests that there is a clear tunnelling component for the reaction at low temperature. The two barriers for forming $\mathrm{H}_{2} \mathrm{CO}$ and $\mathrm{CH}_{3} \mathrm{OH}$ show different temperature dependencies. The formation of methanol becomes relatively more important at higher temperature. Note that the Monte Carlo method automatically treats a reaction in 
Table 2. Reaction rates and barriers for $\mathrm{CO}+\mathrm{H}$ and $\mathrm{H}_{2} \mathrm{CO}+\mathrm{H}$ for different temperatures.

\begin{tabular}{ccccc}
\hline \hline$T$ & \multicolumn{2}{c}{$\mathrm{CO}+\mathrm{H}$} & \multicolumn{2}{c}{$\mathrm{H}_{2} \mathrm{CO}+\mathrm{H}$} \\
& barrier & rate & barrier & rate \\
$(\mathrm{K})$ & $(\mathrm{K})$ & $\left(\mathrm{s}^{-1}\right)$ & $(\mathrm{K})$ & $\left(\mathrm{s}^{-1}\right)$ \\
\hline 12.0 & $390 \pm 40$ & $2 \times 10^{-3}$ & $415 \pm 40$ & $2 \times 10^{-4}$ \\
13.5 & $435 \pm 50$ & $2 \times 10^{-3}$ & $435 \pm 50$ & $2 \times 10^{-3}$ \\
15.0 & $480 \pm 60$ & $3 \times 10^{-3}$ & $470 \pm 60$ & $5 \times 10^{-3}$ \\
16.5 & $520 \pm 70$ & $4 \times 10^{-3}$ & $490 \pm 70$ & $2 \times 10^{-2}$ \\
\hline
\end{tabular}

competition with desorption and hopping. This is in contrast to gas-grain codes, where it must be included explicitly. To describe the chemical processes properly, one should introduce this competition into the gas-grain model.

The errors in the energy barriers reflect the errors due to the uncertainties in the sticking probability, H-atom flux, diffusion, and exact structure of the CO ice.

Molecular hydrogen is formed on the surface with efficiencies ranging from $3 \%(T=16.5 \mathrm{~K})$ to $70 \%(T=12.0 \mathrm{~K})$. However, because of the large excess energy of the formation reaction, the majority of the formed $\mathrm{H}_{2}$ molecules leaves the surface, and the $\mathrm{H}_{2}$ surface abundance is predominantly determined by impinging $\mathrm{H}_{2}$ molecules.

\subsection{Effect of diffusion}

Since the diffusion rates are uncertain, this section discusses the effect of diffusion in more detail. Minimum energy path calculations of the diffusion of a single hydrogen atom on a CO (110) surface (see Appendix B) results in energy barriers ranging from 70 to $170 \mathrm{~K}(\xi=2-5.3)$ depending on the direction of diffusion. The Monte Carlo program considers only one type of diffusion between "flat" sites. This corresponds more closely to the isotropic nature of an amorphous surface. Amorphous surfaces are usually more corrugated than crystalline surfaces, increasing the hopping barrier. The second term in Eq. (5) ensures microscopic reversibility. Figure 10 shows the influence of the diffusion parameter $\xi$ on the $\mathrm{H}_{2} \mathrm{CO}$ and $\mathrm{CH}_{3} \mathrm{OH}$ production. The simulations are carried out in the presence of $\mathrm{H}_{2}$ for $12.0 \mathrm{~K}$ (top) and $15.0 \mathrm{~K}$ (bottom). The difference in diffusion appears to have a larger effect at $15.0 \mathrm{~K}$ than at $12.0 \mathrm{~K}$. Faster diffusion (smaller $\xi$ ) clearly results in less $\mathrm{CH}_{3} \mathrm{OH}$ and $\mathrm{H}_{2} \mathrm{CO}$ production, since the $\mathrm{H}$ atoms are more likely to find each other and to react to form $\mathrm{H}_{2}$. Slower diffusion provides more time for the $\mathrm{H}$ atoms per $\mathrm{CO}$ encounter to cross the reaction barrier and form HCO. In the simulations presented in Figs. 6 and 11, we use $\xi=8$ to reduce the simulation time. This parameter choice results in a ratio $E_{\text {hop }}$ (flat, flat) $/ E_{\text {bind }}$ (flat) of 0.78 , which agrees with the experimentally found ratio for $\mathrm{H}$ atoms on olivine and amorphous carbon (Katz et al. 1999). The amorphocity of the surface may be responsible for such a high ratio.

\subsection{Effect of $\mathrm{H}_{2}$ molecules on the hydrogenation}

All simulations include the deposition of both $\mathrm{H}$ atoms and $\mathrm{H}_{2}$ molecules, which results from the undissociated $\mathrm{H}_{2}$ molecules in the $\mathrm{H}$-beam. If the $\mathrm{H}_{2}$ molecules are excluded from the simulations, the formation of $\mathrm{H}_{2} \mathrm{CO}$ and $\mathrm{CH}_{3} \mathrm{OH}$ is affected in only a limited number of cases of both fast diffusion and high temperature. The presence of $\mathrm{H}_{2}$ appears to have two principle effects: it limits the penetration into the ice and decelerates the $\mathrm{H}$ atoms, since they move through a "sea" of $\mathrm{H}_{2}$. The first effect

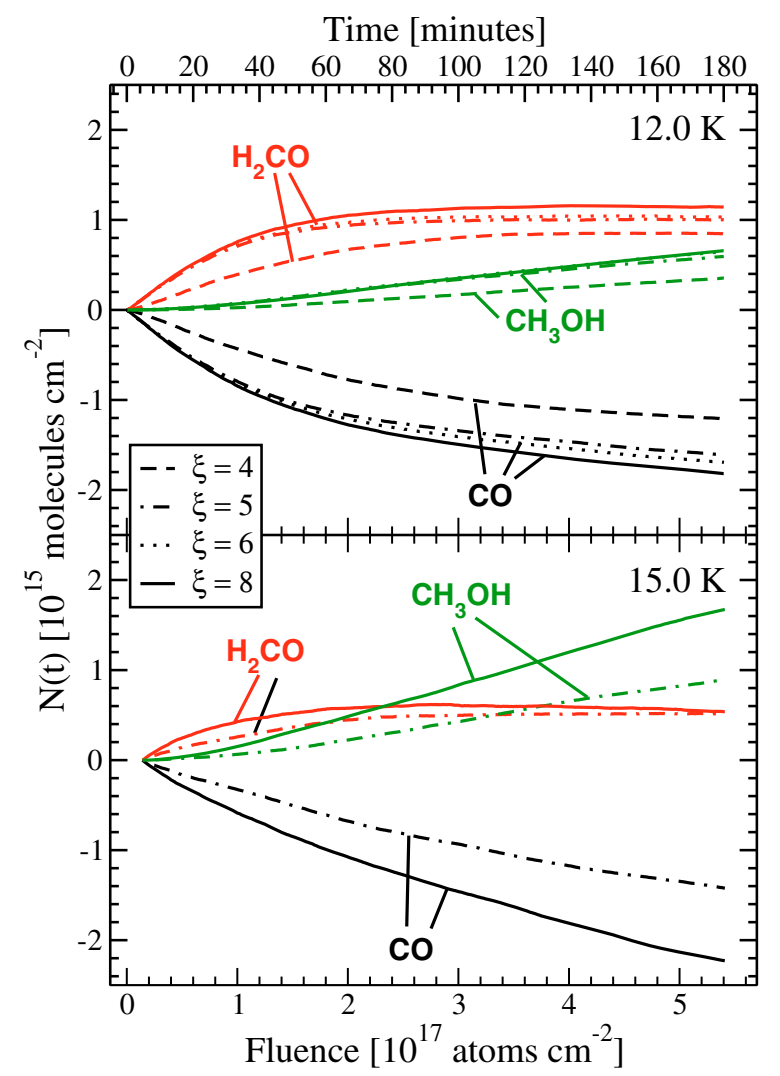

Fig. 10. Monte Carlo simulations of the time evolution of the surface abundance of $\mathrm{CO}, \mathrm{H}_{2} \mathrm{CO}$ and $\mathrm{CH}_{3} \mathrm{OH}$ during $\mathrm{H}$-atom bombardment of $\mathrm{CO}$ ice at $12.0 \mathrm{~K}$ (top) and $15.0 \mathrm{~K}$ (bottom). Reaction barriers for $\mathrm{H}+$ $\mathrm{CO}$ and $\mathrm{H}+\mathrm{H}_{2} \mathrm{CO}$ can be found in Table 2. The diffusion is varied via the parameter $\xi$ (Eq. (5)).

reduces the production rate, whereas the second depends on the reaction barrier.

The experimental results at temperatures higher than $12.0 \mathrm{~K}$ show non-first-order behaviour at early times (exponential decay of $\mathrm{CO}$ ). The $\mathrm{H}_{2} \mathrm{CO}$ production rate increases until 30 and $50 \mathrm{~min}$ of exposure for $T=13.5$ and $15.0 \mathrm{~K}$, respectively. After this time, the $\mathrm{H}_{2} \mathrm{CO}$ and $\mathrm{CH}_{3} \mathrm{OH}$ follow the expected first order behaviour. None of the simulations in Fig. 10 show this trend. The only mechanism capable of describing this phenomenon is an increasing effective $\mathrm{H}$-atom flux with time. This increase in effective flux can be cased by an increase in the sticking of atomic hydrogen to the surface. Since the incoming $\mathrm{H}$ atoms are relatively warm, they need to dissipate this extra energy into the surface to stick. Because $\mathrm{CO}$ is relatively heavy compared to the $\mathrm{H}$ atoms, this energy dissipation will be inefficient, and most of the $\mathrm{H}$ atoms will scatter back into the gas phase. Once the surface abundance of the much lighter $\mathrm{H}_{2}$ molecules increases, the sticking of the $\mathrm{H}$ atoms to the surface will increase as well. We assume a $1 \%$ sticking for $\mathrm{H}$ atoms and $\mathrm{H}_{2}$ molecules on a bare $\mathrm{CO}$ surface and a $65 \%$ sticking of $\mathrm{H}$ atoms on a surface that is fully covered with $\mathrm{H}_{2}$. The sticking probability is further assumed to grow linearly with the $\mathrm{H}_{2}$ coverage. The $\mathrm{H}_{2}$ surface abundance reaches a constant level of 0.39 ML after a few minutes for $T$ is $12.0 \mathrm{~K}$. This results in a sticking of $\mathrm{H}$ atoms to the surface of $26 \%$. For higher temperatures, it is noticeably longer time before to a steady state is reached, explaining the non-linear behaviour at early times and inferring a lower final sticking probability. The solid lines in Fig. 6 include this mechanism. 
As mentioned earlier, Watanabe \& Kouchi (2002) concluded that the temperature of the beam has little effect on the hydrogenation process, which seems to contradict our $\mathrm{H}_{2}$ argument. However, their experiments were carried out at $10 \mathrm{~K}$, where the surfaces are covered with hydrogen atoms early on in the experiment because of the enhanced sticking at low temperatures. They further reported an unknown flux difference between the cold and warm beam, which makes quantifying the sticking probability using these experiments not possible. In conclusion, the temperature of the beam can affect the effective flux of $\mathrm{H}$ atoms landing on the surfaces, but it does not introduce additional energetic effects that influence the crossing of the barrier.

\section{CO hydrogenation under interstellar conditions}

Based on the fitting results in the previous section, the Monte Carlo routine can now be used to simulate $\mathrm{CO}$ hydrogenation reactions under interstellar conditions. An important ingredient is the $\mathrm{H}$-atom density in the cloud. As in our laboratory beam, the gas in dense clouds consists of a mix of $\mathrm{H}$ and $\mathrm{H}_{2}$. Under steady-state conditions, the balance of the rates of $\mathrm{H}_{2}$ formation on grains and $\mathrm{H}_{2}$ destruction by cosmic rays infers an $\mathrm{H}$-atom density of around $1 \mathrm{~cm}^{-3}$ (Hollenbach \& Salpeter 1971). This $\mathrm{H}$-atom number density is independent of the total density because both the formation and destruction rates scale with density. Before steady-state is reached, however, the H-atom density may be higher because the timescale for $\mathrm{H}$ to $\mathrm{H}_{2}$ conversion is long $\left(\sim 10^{7} \mathrm{yr}\right)$, starting from a purely atomic low-density cloud (Goldsmith et al. 2007). Our model assumes a constant H-atom density of $10 \mathrm{~cm}^{-3}$. Our other model parameters are a gas temperature of $20 \mathrm{~K}$ and dust temperatures of 12.0 and $16.5 \mathrm{~K}$. A $\mathrm{CO}$ surface is then simulated for $2 \times 10^{5} \mathrm{yr}$, which corresponds to a fluence of $10.8 \times 10^{17}$ atoms $\mathrm{cm}^{-2}$. Note that half of this fluence was reached in our experiments. Because the $\mathrm{H}$-atom velocities are low, the sticking of $\mathrm{H}$ atoms to the $\mathrm{CO}$ ice is not varied in the simulations, but remains constant at $100 \%$.

The starting configuration for the simulations is a layer of pure CO ice. This is believed to be representative for the top layers of the grain mantles at the centre of a high-density collapsing cloud. Here, the ice layer is observed to consist of predominantly CO ice as the result of "catastrophic" CO freeze-out (Pontoppidan 2006; Pontoppidan et al. 2008). More heterogeneous ice layers are formed at lower densities where $\mathrm{CO}$ and $\mathrm{H}_{2} \mathrm{O}$ are mixed, or towards the centre of proto-stellar envelops or proto-planetary disks where the dust has been heated and CO has desorbed from the top layers.

Figure 11 (top) shows the resulting time evolution of $\mathrm{CO}$, $\mathrm{H}_{2} \mathrm{CO}$, and $\mathrm{CH}_{3} \mathrm{OH}$ ice (thick lines) for $12.0 \mathrm{~K}$. The thin lines in Fig. 11 represent the direct scaling of the simulations of the experiment on interstellar timescales. The $\mathrm{H}_{2} \mathrm{CO} / \mathrm{CH}_{3} \mathrm{OH}$ ratio of the low flux simulation is very different from the scaled experimental simulation. The reason for this is that in the laboratory environment twice as many hydrogen atoms react with each other to form $\mathrm{H}_{2}$ than are involved in the four $\mathrm{CO}$ hydrogenation reactions since the surface density is relatively high. For interstellar conditions, the $\mathrm{CO}$ hydrogenation reactions dominate and only $<5 \%$ of the reacting $\mathrm{H}$ atoms are converted into $\mathrm{H}_{2}$. A second effect that changes the time evolution of the ISM is the difference in sticking. Under laboratory conditions, the sticking probability is much lower since the incoming $\mathrm{H}$ atoms at room temperature cannot release their energy very efficiently into the $\mathrm{CO}$ ice. The presence of $\mathrm{H}_{2}$ on the surface may have a positive effect on the sticking probability. In the ISM, the incoming atoms are much colder and energy dissipation will not be a

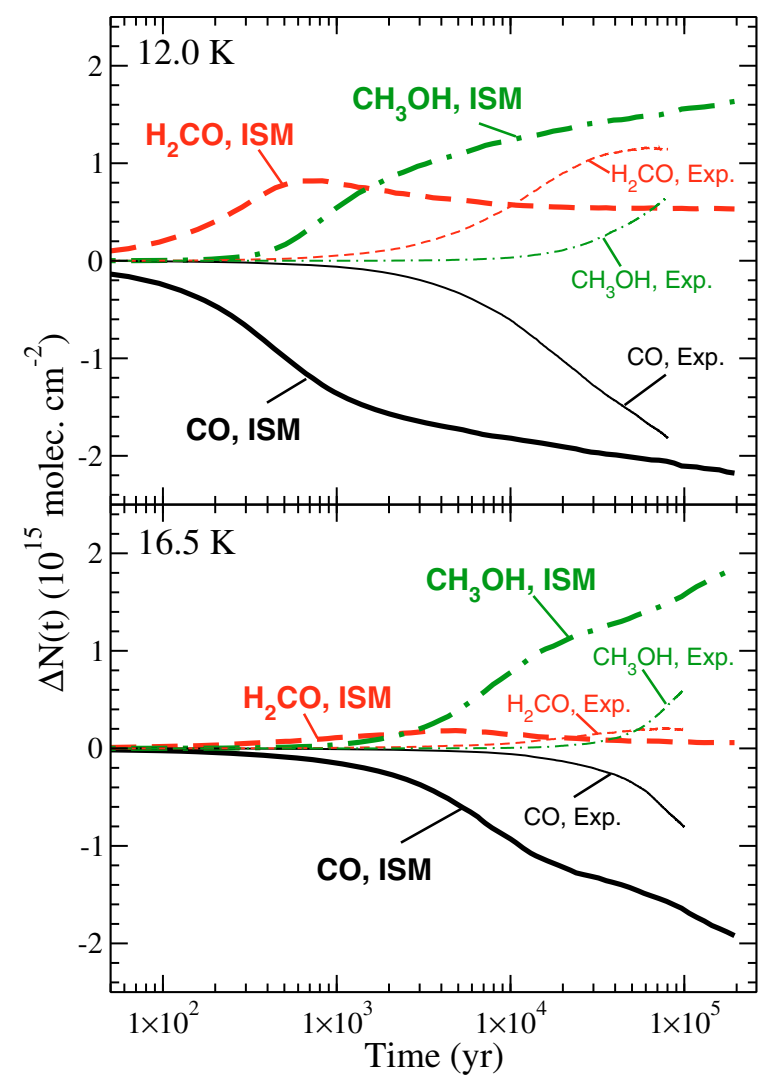

Fig. 11. Monte Carlo simulations of CO-ice hydrogenation at 12.0 (top) and $16.5 \mathrm{~K}$ (bottom). A constant atomic hydrogen gas phase density of $10 \mathrm{~cm}^{-3}$ and a gas temperature of $20 \mathrm{~K}$ is assumed. Thick lines represent interstellar conditions, thin lines are the scaled experimental simulations. The results are shown as the change in column density compared with $t=0 \mathrm{yr}$.

limiting factor for the sticking of $\mathrm{H}$ atoms into $\mathrm{CO}$ ice. This can be modelled using Monte Carlo simulations but only after deriving the energy barriers by fitting the laboratory data.

The bottom panel in Fig. 11 shows similar trends for $16.5 \mathrm{~K}$. Again the onset of $\mathrm{H}_{2} \mathrm{CO}$ and $\mathrm{CH}_{3} \mathrm{OH}$ formation is at much lower fluences than in the experiment. At the end of the simulation, nearly all $\mathrm{H}_{2} \mathrm{CO}$ has been converted into $\mathrm{CH}_{3} \mathrm{OH}$. This is in contrast to the $12.0 \mathrm{~K}$ simulations, where a constant nonzero amount of $\mathrm{H}_{2} \mathrm{CO}$ remains after $2 \times 10^{5} \mathrm{yr}$. The crossover point from $\mathrm{H}_{2} \mathrm{CO}$-rich to $\mathrm{CH}_{3} \mathrm{OH}$-rich ice occurs at slightly later times at $16.5 \mathrm{~K}$ compared to $12.0 \mathrm{~K}$. This can clearly be seen in Fig. 12, which plots the $\mathrm{H}_{2} \mathrm{CO} / \mathrm{CH}_{3} \mathrm{OH}$ ratio for both temperatures. At early times, this ratio is similar for 12.0 and $16.5 \mathrm{~K}$. At $t>10^{3} \mathrm{yr}$, the ratio starts to level off at $12.0 \mathrm{~K}$, while it still decreases rapidly at $16.5 \mathrm{~K}$. The noise in the curve for $16.5 \mathrm{~K}$ below $t=5 \times 10^{3} \mathrm{yr}$ is due to the low abundances of $\mathrm{H}_{2} \mathrm{CO}$ and $\mathrm{CH}_{3} \mathrm{OH}$.

In space, the $\mathrm{H}_{2} \mathrm{CO} / \mathrm{CH}_{3} \mathrm{OH}$ ice ratio has been determined directly for only three high-mass young stellar objects (YSOs): W 33A, NGC 7538 IRS9, and AFGL 70009S, with inferred ratios ranging from 0.09 to 0.51 (Keane et al. 2001; Gibb et al. 2004). The laboratory curves for the $\mathrm{H}_{2} \mathrm{CO}$ and $\mathrm{CH}_{3} \mathrm{OH}$ production show that $\mathrm{H}_{2} \mathrm{CO}$ is more or equally abundant during most of our experiments. Thus, values as low as 0.09-0.51 cannot easily be reproduced in the experiments. However, the Monte Carlo simulations for interstellar conditions have a crossover from $\mathrm{H}_{2} \mathrm{CO}$-rich to $\mathrm{CH}_{3} \mathrm{OH}$-rich ice at significantly earlier times than the experimental curves and $\mathrm{H}_{2} \mathrm{CO} / \mathrm{CH}_{3} \mathrm{OH}$ ratio of 0.51 


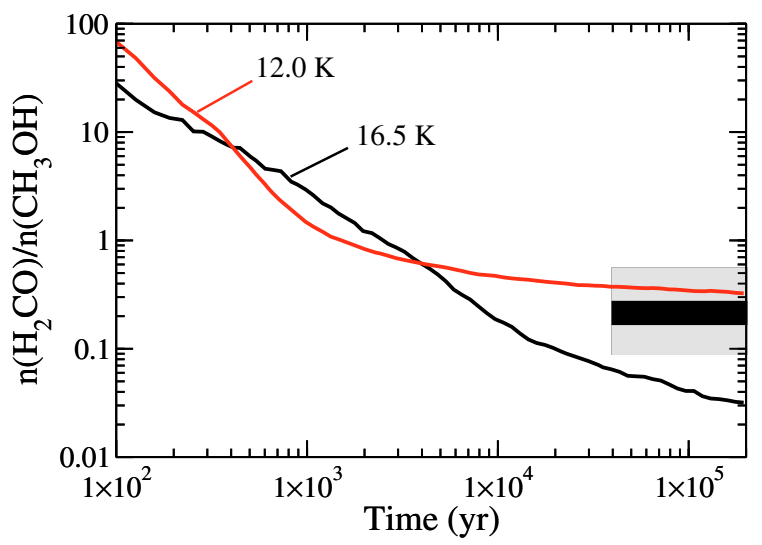

Fig. 12. The $\mathrm{H}_{2} \mathrm{CO} / \mathrm{CH}_{3} \mathrm{OH}$ ratio as a function of time obtained from the Monte Carlo simulations of $\mathrm{CO}$ hydrogenation at 12.0 and $16.5 \mathrm{~K}$ under ISM conditions (see Fig. 11). The grey box indicates Spitzer ice observations, the black box gas phase observations.

is obtained after $5 \times 10^{3} \mathrm{yr}$ at $T_{\text {dust }}=12 \mathrm{~K}$. Grains at higher temperatures will have this crossover at even earlier times and for grains with $T_{\text {dust }}=16.5 \mathrm{~K}$, a $\mathrm{H}_{2} \mathrm{CO} / \mathrm{CH}_{3} \mathrm{OH}$ ratio of even 0.09 is obtained after $2 \times 10^{4} \mathrm{yr}$. Thus, the observed ratios are in agreement with the models discussed above for chemical timescales $>2 \times 10^{4} \mathrm{yr}$, which is consistent with the estimated ages of these high-mass protostars of a few $10^{4}-10^{5} \mathrm{yr}$ (Hoare et al. 2007).

$\mathrm{CH}_{3} \mathrm{OH}$ ice has also been detected toward low-mass YSOs with abundances ranging from $<1 \%$ to more than $25 \%$ of the $\mathrm{H}_{2} \mathrm{O}$ ice abundance (Pontoppidan et al. 2003; Boogert et al. 2008). An interesting example is the Class 0 protostar Serpens SMM 4, for which a particularly high $\mathrm{CH}_{3} \mathrm{OH}$ abundance of $28 \%$ with respect to $\mathrm{H}_{2} \mathrm{O}$ ice was deduced for the outer envelope (Pontoppidan et al. 2004). The upper limit to the $\mathrm{H}_{2} \mathrm{CO}$ ice abundance implies a $\mathrm{H}_{2} \mathrm{CO} / \mathrm{CH}_{3} \mathrm{OH}$ ratio $<0.18$, implying an age $>1 \times 10^{4} \mathrm{yr}$ at $16.5 \mathrm{~K}$. This is consistent with the estimated timescale for heavy freeze out in low-mass YSOs of $10^{5 \pm 0.5} \mathrm{yr}$, including both the pre-stellar and proto-stellar phases (Jørgensen et al. 2005).

Other observational constraints come from sub-millimetre observations of the gas in a sample of massive hot cores, where a constant ratio of $\mathrm{H}_{2} \mathrm{CO} / \mathrm{CH}_{3} \mathrm{OH}$ of $0.22 \pm 0.05$ was found (Bisschop et al. 2007b). If both the observed $\mathrm{H}_{2} \mathrm{CO}$ and $\mathrm{CH}_{3} \mathrm{OH}$ have just evaporated freshly off the grains and if they have not been affected by subsequent gas-phase chemistry, the observed ratio should reflect the ice abundances. This ratio is roughly consistent with the asymptotic value reached by the $12 \mathrm{~K}$ model. This remarkably constant abundance ratio implies that very similar physical conditions (e.g., dust temperatures, H-atom abundances) exist during ice formation.

In contrast, since the $\mathrm{CH}_{3} \mathrm{OH}$ ice abundance with respect to that of $\mathrm{H}_{2} \mathrm{O}$ is known to vary by more than an order of magnitude, both local conditions and timescales appear to play a role. Note, however, that for $\mathrm{CH}_{3} \mathrm{OH}$ abundances as large as $25 \%$ (columns as large as $10^{18} \mathrm{~cm}^{-2}$ ), the $\mathrm{CH}_{3} \mathrm{OH}$ layer is approximately $25 \mathrm{ML}$ thick $\left(0.25 \times n\left(\mathrm{H}_{2} \mathrm{O}\right) /\left(n_{\text {dust }} \times\right.\right.$ $<$ binding sites per grain $>)=0.25 \times 10^{-4} /\left(10^{-12} \times 10^{6}\right)=$ $25 \mathrm{ML})$, much more than can be produced from just the upper $4 \mathrm{ML}$ of the $\mathrm{CO}$ ice. Thus, conversion of $\mathrm{CO}$ into $\mathrm{CH}_{3} \mathrm{OH}$ ice must in these cases occur simultaneously with the freeze-out and building up of the $\mathrm{CO}$ layer. Pure $\mathrm{CO}$ ice can also easily desorb as soon as the protostar heats up. This complicates the use of $\mathrm{CH}_{3} \mathrm{OH} / \mathrm{CO}$ ice as an evolutionary probe. A proper model of interstellar $\mathrm{CH}_{3} \mathrm{OH}$ ice formation should therefore include the effects of the variations in CO-ice abundances and dust temperatures in the pre- and protostellar phases, and account for the differences in timescales for $\mathrm{CH}_{3} \mathrm{OH}$-ice formation compared with those of $\mathrm{CO}$ adsorption and desorption. This paper provides the necessary molecular data to compile such a model.

\section{Conclusion}

The present paper shows that the formation of methanol by successive hydrogenation of $\mathrm{CO}$ and $\mathrm{H}_{2} \mathrm{CO}$ is efficient under various laboratory conditions covering $T_{\text {surf }}=12-20 \mathrm{~K}$, ice thicknesses between $1 \times 10^{15}$ and $1 \times 10^{16}$ molecules $\mathrm{cm}^{-2}$ equivalent to 1 and $10 \mathrm{ML}$ bulk CO, and $\mathrm{H}$-atom fluxes between $1 \times 10^{12}$ and $5 \times 10^{13} \mathrm{~cm}^{-2} \mathrm{~s}^{-1}$. Our results show that the discrepancy between Hiraoka et al. (2002) and Watanabe \& Kouchi (2002) was indeed caused mainly by the use of different $\mathrm{H}$-atom fluxes and we agree with the latter group of authors that $\mathrm{CH}_{3} \mathrm{OH}$ is formed at low temperature. On the basis of this, the surface hydrogenation of $\mathrm{CO}$ can now be safely used to explain the majority of the formed methanol in the interstellar medium, where it is a key molecule in the synthesis of more complex molecules.

Energy barriers for the $\mathrm{H}+\mathrm{CO}$ and $\mathrm{H}_{2} \mathrm{CO}+\mathrm{H}$ reactions are obtained by fitting Monte Carlo simulation results to the experimental data. Using these barriers, the methanol production is simulated for interstellar conditions. The obtained $\mathrm{H}_{2} \mathrm{CO}$ and $\mathrm{CH}_{3} \mathrm{OH}$ abundances do not scale directly with fluence because of the different relative importance of $\mathrm{H}_{2}$ production and $\mathrm{CO}$ hydrogenation in space compared with the laboratory, as can be clearly seen by comparing the thick and thin lines in Fig. 11. However, laboratory experiments are required to derive the necessary rates that serve as input to the Monte Carlo program. The obtained $\mathrm{H}_{2} \mathrm{CO} / \mathrm{CH}_{3} \mathrm{OH}$ ratios for the interstellar simulations are in closer agreement with observational limits than a direct translation of the experimental observations.

Monte Carlo simulations of the hydrogenation process show that the presence of $\mathrm{H}_{2}$ has three effects: it promotes the sticking of the warm $\mathrm{H}$ atoms, it limits the penetration into the ice, and it slows down the diffusion of $\mathrm{H}$ atoms. The first effect will be negligible under interstellar conditions since the incoming $\mathrm{H}$ atoms will be cold already and the sticking probability will therefore be high regardless of the substrate. The latter two effects will be important and are similar to the conditions in the laboratory for also a high $\mathrm{H}_{2}$ abundance.

The experiments show that the hydrogenation process is thickness independent for layers thicker than $4 \times 10^{15} \mathrm{~cm}^{-2}$, and that the active layer, which contains only a limited amount of $\mathrm{CO}$ after a steady state is reached, becomes slightly thicker with temperature. For temperatures higher than $15.0 \mathrm{~K}$, a clear drop in the production rate of methanol is observed. This is probably due to two effects: the desorption of $\mathrm{H}$ atoms becoming important and the sticking of $\mathrm{H}$ atoms being reduced because of the low $\mathrm{H}_{2}$ surface abundance. Both effects cause the $\mathrm{H}$ surface abundance to drop substantially at those temperatures and therefore reduce the probability of hydrogenation reactions occurring in the laboratory. Simulations of $\mathrm{CO}$ hydrogenation in space show a strong temperature dependence of the $\mathrm{H}_{2} \mathrm{CO} / \mathrm{CH}_{3} \mathrm{OH}$ ratio over several orders of magnitude. The $\mathrm{CH}_{3} \mathrm{OH}$ abundance changes with time, temperature, and fluence.

Acknowledgements. Part of this work was supported by the Netherlands Research School for Astronomy, NOVA, and Netherlands Organization for Scientific Research (NWO) through a VENI grant. We thank Stephan Schlemmer and Helen Fraser for their contribution during the first construction phase and Gijsbert Verdoes, Martijn Witlox and Ewie de Kuyper from the Fijn Mechanische Dienst for their support. Ayman Al-Halabi, Lou Allamandola, 
Eric Herbst, Xander Tielens, Klaus Pontoppidan, and Zainab Awad have contributed to this work through long and inspiring discussions.

\section{Appendix A: Absolute and relative $\mathrm{H}$-atom flux determination}

\section{A.1. Absolute flux determination}

The (accuracy of the) absolute value of the $\mathrm{H}$-atom flux at the ice surface is obtained by estimating lower and upper limits in two independent ways. We exemplify here the $\mathrm{H}$-atom flux determination for the case of our standard values with an $\mathrm{H}_{2}$ pressure in the chamber of $p_{\mathrm{H}_{2}}=1 \times 10^{-5}$ mbar and a filament temperature of $T=2300 \mathrm{~K}$.

The lower limit to the absolute flux is directly available from the experimental results presented in Ioppolo et al. (2008). That paper discusses the $\mathrm{H}_{2} \mathrm{O}_{2}$ and $\mathrm{H}_{2} \mathrm{O}$ production from $\mathrm{H}$-atom bombardment of $\mathrm{O}_{2}$-ice in time using the same setup and settings. During the first hour, $\mathrm{H}_{2} \mathrm{O}_{2}$ and $\mathrm{H}_{2} \mathrm{O}$ are produced with an almost constant production rate of $6.0 \times 10^{12}$ molecules $\mathrm{cm}^{-2} \mathrm{~s}^{-1}$. Since both molecules contain two hydrogen atoms, this means that the $\mathrm{H}$-atom flux should be at least twice this value. Assuming a conservative sticking probability of hydrogen atoms at $300 \mathrm{~K}$ to $\mathrm{O}_{2}$-ice between $12 \mathrm{~K}$ and $28 \mathrm{~K}$ of at most $50 \%$, we determine a lower limit to the flux of $2.4 \times 10^{13} \mathrm{~cm}^{-2} \mathrm{~s}^{-1}$.

The determination of the upper limit to the H-atom flux is more elaborate and involves several steps. Figure 1 shows that the hydrogen atoms travel from the source through the atomicline chamber to a quartz pipe, where the atoms are collisionally cooled and then travel through the main chamber onto the substrate. The final H-atom flux is then determined by

$\phi_{\mathrm{H}}=\frac{N_{\mathrm{H}, \text { source }} k_{1} k_{2} p r}{A}$,

where $N_{\mathrm{H} \text {,source }}$ is the number of hydrogen atoms leaving the source per second, $k_{1}$ is the coupling efficiency between the source and quartz pipe, $k_{2}$ is the coupling efficiency between the quartz pipe and the ice surface, $p$ accounts for the pressure drop between the two chambers, $r$ for the loss in $\mathrm{H}$-atoms because of recombinations in the quartz pipe, and $A$ is the surface area that is exposed by the H-atom beam.

Our specific hydrogen source, used in the experiments described here, has been tested prior to delivery at the Forschungszentrum in Jülich where the flux, solid angle, and dissociation rate have been measured for a wide range of $\mathrm{H}_{2}$ pressures and filament temperatures. The set-up used for these calibration experiments is described in Tschersich \& von Bonin (1998). These measurements confirmed that there is little variation between individual instruments, since nearly identical rates were obtained by Tschersich \& von Bonin (1998) and Tschersich (2000) and later by Tschersich et al. (2008) for different H-atom sources of the same type. From the flux and dissociation rate measured in Jülich, $N_{\mathrm{H} \text {,source }}$ can be obtained as well as $k_{1}$ using the solid angle information. In our example case, $4.1 \times 10^{16} \mathrm{H}$ atoms s${ }^{-1}$ leave the $\mathrm{H}$-atom source and $44 \%$ of these atoms enter the quartz pipe, which is located at a distance of $1.5 \mathrm{~cm}$.

The pipe is designed so that the atoms cannot reach the substrate directly and that the number of hydrogen recombinations is kept to a minimum. This is achieved by using a short pipe with a high diameter/length ratio and choosing quartz, which is known to have a low recombination efficiency. Following Walraven \& Silvera (1982), a theoretical estimate of the number of recombinations in the pipe can be determined, considering the specific shape and material. This reduces the H-atom flux by another $27 \%$. The pipe ends in close proximity to the cryogenic surface. The use of a pipe instead of a pinhole or a slit results in a focused $\mathrm{H}$-atom beam for which the flux can be determined to relatively low uncertainty. From geometric considerations, a minimum solid angle can be estimated. This will suffice, since our aim is to obtain an upper limit to the flux. The H-atom beam covers $A=4.9 \mathrm{~cm}^{2}$ of the substrate that is located $3 \mathrm{~cm}$ behind the quartz pipe. This spot falls completely on the surface and $k_{2}$ can readily be assumed to be unity.

Finally, the pressure drop between the source and the main chamber can be determined in two ways: by a calculation using the conductance of the pipe and the pumping speed, and by measuring the pressures in both chambers using undissociated beams. Both results are in reasonable agreement, leading to $p=3.2 \times 10^{-2}$.

Our upper limit to the flux is now

$$
\begin{aligned}
\phi_{\mathrm{H}} & =\frac{4.1 \times 10^{16} \cdot 0.44 \cdot 1 \cdot 3.2 \times 10^{-2} \cdot 0.73}{4.9} \\
& =8.6 \times 10^{13} \mathrm{~cm}^{-2} \mathrm{~s}^{-1} .
\end{aligned}
$$

Deviations from this upper limit are expected to be due to a lower $k_{1}$ value, because of misalignments between the source and the entrance of the quartz pipe, an underestimation of the solid angle of the exiting beam from the quartz pipe (lower $k_{1}$ and higher $A$ ), more recombinations in the pipe or backscattering of atoms from the quartz pipe, to the chamber of the H-atom source.

The value of flux adopted in the present paper is the resultant intermediate $\mathrm{H}$-atom flux of $5 \times 10^{13} \mathrm{~cm}^{-2} \mathrm{~s}^{-1}$, which is within a factor of 2 of the upper and lower limits. It should be noted that this is a conservative error, since the true lower and higher flux limits are likely to be higher and lower, respectively.

\section{A.2. Relative flux determination}

The accuracy in the relative flux is particularly important to the conclusion presented in this paper, more so than the absolute value. For this we use the $\mathrm{CO}$-hydrogenation data obtained from the experiments. Figure A. 1 shows the $\mathrm{CO}, \mathrm{H}_{2} \mathrm{CO}$ and $\mathrm{CH}_{3} \mathrm{OH}$ evolution as a function of fluence for three different fluxes. The fluences are calculated using the flux determination as described above. The three curves clearly overlap, which means that the accuracy of the relative fluxes is well within our error bars. We conclude that the accuracy in the relative flux is substantially higher than the accuracy of the absolute flux, well below $50 \%$. One of the main conclusions of the paper, that the discrepancy between the two Japanese groups is due to a difference in flux, as envisaged by Hidaka et al. (2004), is therefore robust.

Finally, reproducing the same experiments on different days over the course of several months showed that reproducibility over periods from day-to-day to months is excellent, to within a few percent.

\section{Appendix B: Binding energy calculations}

To calculate binding energies and barriers to diffusion, recentlydeveloped $\mathrm{CO}-\mathrm{CO}$ and $\mathrm{H}-\mathrm{CO}$ potentials are used. Takahashi and van Hemert (in prep.) have fitted high level electronic structure (coupled cluster) calculations of the $\mathrm{CO}-\mathrm{CO}$ dimer to an analytic potential consisting of partial charges on the atoms and the centres of mass of the CO molecules, atom-based Lennard-Jones type interactions, and Morse potentials for the intramolecular 


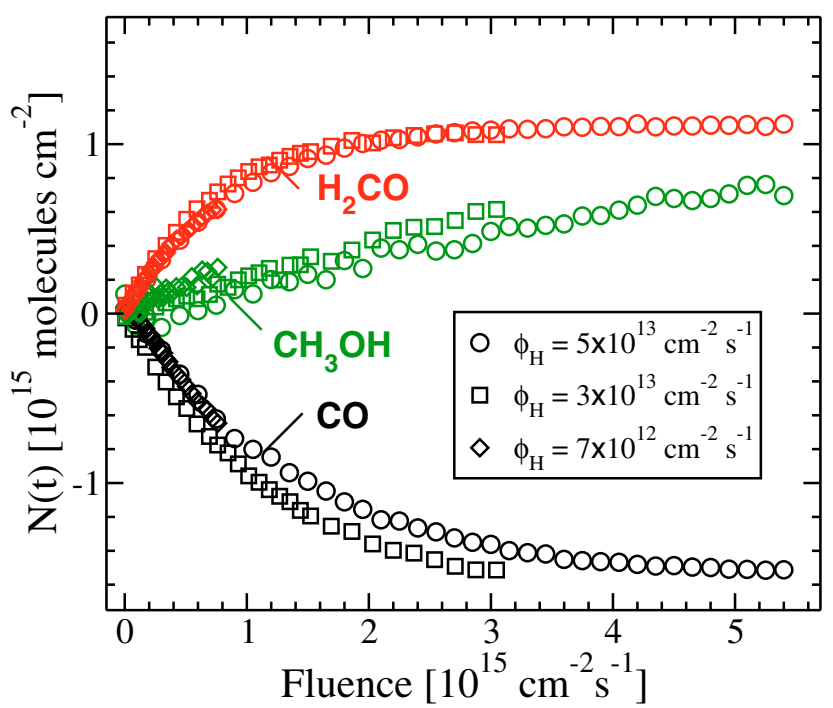

Fig. A.1. Time evolution of the surface abundance (in molecules $\mathrm{cm}^{-2}$ ) of $\mathrm{CO}, \mathrm{H}_{2} \mathrm{CO}$ and $\mathrm{CH}_{3} \mathrm{OH}$ during $\mathrm{H}$-atom bombardment of $\mathrm{CO}$ ice at $12.0 \mathrm{~K}$ with three different $\mathrm{H}$ fluxes of $5 \times 10^{13}, 3 \times 10^{13}$, and $7 \times 10^{12} \mathrm{~cm}^{-2}$.

$\mathrm{C}-\mathrm{O}$ interaction. In the work by Andersson et al. (in prep.), a potential for the interaction between a hydrogen atom and $\mathrm{CO}$ has been calculated by fitting damped dispersion and exponential repulsion potentials to coupled cluster calculations.

Using the CO-CO potential, a CO (110) surface has been created consisting of $528 \mathrm{CO}$ molecules in 11 monolayers in a cell with dimensions $33.8 \times 31.8 \AA$ in the surface plane. By applying periodic boundary conditions, an infinite surface is created. Binding energies have been calculated by performing energy minimisations for $\mathrm{H}$ atoms at different sites on top of and inside the $\mathrm{CO}$ surface and by comparing to the energy when the hydrogen is far away from the surface. In the same manner, the binding energy for a CO molecule in the top layer has been calculated. In all instances, the top 3 monolayers of the ice have been allowed to relax.

To calculate the energy barriers to diffusion both on and into the surface, the nudged elastic band (NEB) method (Jónsson et al. 1998) is used initially to map out the minimum energy path (MEP) connecting two potential minima. To fine-tune the barrier height, the Lanczos method is used to optimise the saddle point of the potential energy (Olsen et al. 2004).

\section{References}

Awad, Z., Chigai, T., Kimura, Y., Shalabiea, O. M., \& Yamamoto, T. 2005, ApJ, 626,262

Bisschop, S. E. 2007, Ph.D. Thesis, Leiden Observatory, Leiden University
Bisschop, S. E., Fuchs, G. W., van Dishoeck, E. F., \& Linnartz, H. 2007a, A\&A, 474, 1061

Bisschop, S. E., Jørgensen, J. K., van Dishoeck, E. F., \& de Wachter, E. B. M. 2007b, A\&A, 465, 913

Boogert, A. C. A., Pontoppidan, K. M., Knez, C., et al. 2008, ApJ, 678, 985

Bouwman, J., Ludwig, W., Awad, Z., et al. 2007, A\&A, 476, 995

Charnley, S. B., Tielens, A. G. G. M., \& Millar, T. J. 1992, ApJ, 399, L71

Cuppen, H. M., \& Herbst, E. 2007, ApJ, 668, 294

Garrod, R., Park, I. H., Caselli, P., \& Herbst, E. 2006, Disc. Faraday Soc., 133, 5

Geppert, W. D., Thomas, R. D., Ehlerding, A., et al. 2005, J. Phys.: Conf. Ser., 4, 26

Gibb, E. L., Whittet, D. C. B., Boogert, A. C. A., \& Tielens, A. G. G. M. 2004, ApJS, 151, 35

Goldsmith, P. F., Li, D., \& Krčo, M. 2007, ApJ, 654, 273

Hidaka, H., Watanabe, N., Shiraki, T., Nagaoka, A., \& Kouchi, A. 2004, ApJ, 614,1124

Hiraoka, K., Miyagoshi, T., Takayama, T., Yamamoto, K., \& Kihara, Y. 1998, ApJ, 498, 710

Hiraoka, K., Sato, T., Sato, S., et al. 2002, ApJ, 577, 265

Hoare, M. G., Kurtz, S. E., Lizano, S., Keto, E., \& Hofner, P. 2007, in Protostars and Planets V, ed. B. Reipurth, D. Jewitt, \& K. Keil, 181

Hollenbach, D., \& Salpeter, E. E. 1971, ApJ, 163, 155

Ioppolo, S., Cuppen, H. M., Romanzin, C., van Dishoeck, E. F., \& Linnartz, H. 2008, ApJ, 686, 1474

Jónsson, H., Mills, G., \& Jacobsen, K. W. 1998, Nudged Elastic Band Method for Finding Minimum Energy Paths of Transitions, ed. B. J. Berne, G. Ciccotti, \& D. F. Coker (Singapore: World Scientific), 385

Jørgensen, J. K., Schöier, F. L., \& van Dishoeck, E. F. 2005, A\&A, 435, 177

Katz, N., Furman, I., Biham, O., Pirronello, V., \& Vidali, G. 1999, ApJ, 522, 305

Keane, J. V., Tielens, A. G. G. M., Boogert, A. C. A., Schutte, W. A., \& Whittet, D. C. B. 2001, A\&A, 376, 254

Kouchi, A. 1990, J. Cryst. Growth, 99, 1220

Miyauchi, N., Hidaka, H., Chigai, T., et al. 2008, Chem. Phys. Lett., 456, 27

Nagaoka, A., Watanabe, N., \& Kouchi, A. 2005, ApJS, 624, L29

Olsen, R. A., Kroes, G. J., Henkelman, G., Arnaldsson, A., \& Jónsson, H. 2004, J. Chem. Phys., 121, 9776

Palumbo, M. E., \& Strazzulla, G. 1993, A\&A, 269, 568

Pontoppidan, K. M. 2006, A\&A, 453, L47

Pontoppidan, K. M., Dartois, E., van Dishoeck, E. F., Thi, W.-F., \& d'Hendecourt, L. 2003, A\&A, 404, L17

Pontoppidan, K. M., van Dishoeck, E. F., \& Dartois, E. 2004, A\&A, 426, 925

Pontoppidan, K. M., Boogert, A. C. A., Fraser, H. J., et al. 2008, ApJ, 678, 1005

Sandford, S. A., Allamandola, L. J., Tielens, A. G. G. M., \& Valero, G. J. 1988, ApJ, 329, 498

Teolis, B. D., Loeffler, M. J., Raut, U., Famá, M., \& Baragiola, R. A. 2007, Icarus, 190, 274

Tielens, A. G. G. M., \& Charnley, S. B. 1997, Orig. Life Evol. Biosph., 27, 23

Tielens, A. G. G. M., \& Hagen, W. 1982, A\&A, 114, 245

Tschersich, K. G. 2000, J. Appl. Phys., 87, 2565

Tschersich, K. G., \& von Bonin, V. 1998, J. Appl. Phys., 84, 4065

Tschersich, K. G., Fleischhauer, J. P., \& Schuler, H. 2008, J. Appl. Phys., 104, 034908

Vegard, I. 1930, Z. Physik, 61, 185

Walraven, J. T. M., \& Silvera, I. F. 1982, Rev. Sci. Instr., 53, 1167

Watanabe, N., \& Kouchi, A. 2002, ApJ, 571, L173

Watanabe, N., Shiraki, T., \& Kouchi, A. 2003, ApJ, 588, L121

Watanabe, N., Nagaoka, A., Shiraki, T., \& Kouchi, A. 2004, ApJ, 616, 638

Watanabe, N., Hidaka, H., \& Kouchi, A. 2006, in Astrochemistry - From Laboratory Studies to Astronomical Observations, ed. R. I. Kaiser, P. Bernath, Y. Osamura, S. Petrie, \& A. M. Mebel, AIP Conf. Ser., 855, 122 